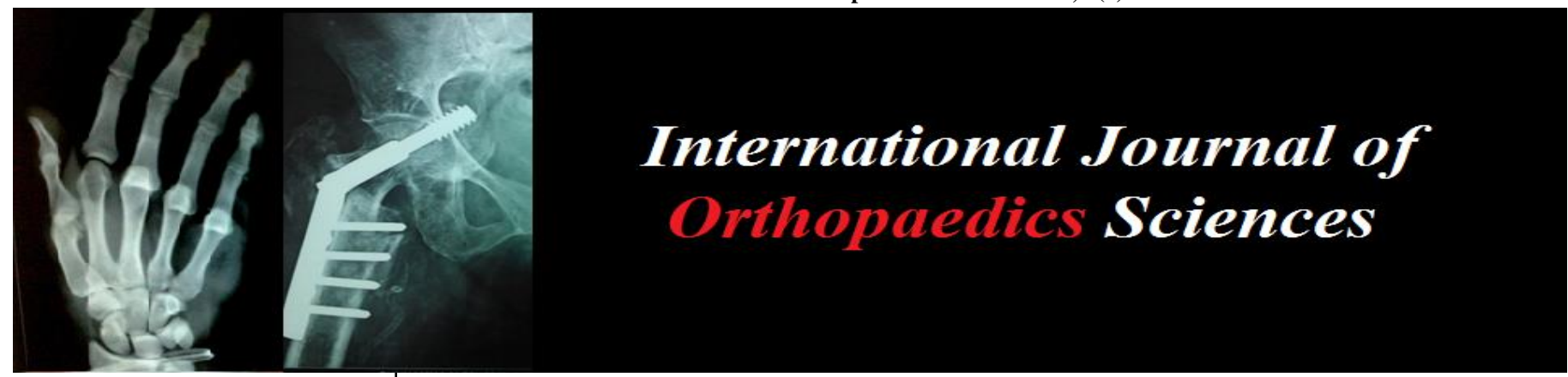

E-ISSN: 2395-1958

P-ISSN: 2706-6630

IJOS 2020; 6(4): 40-43

(C) 2020 IJOS

www.orthopaper.com

Received: 25-08-2020

Accepted: 29-09-2020

Dr. Kanakachalapathi Assistant Professor,

Department of Orthopedics,

Raichur Institute of Medical

Sciences, Raichur, Karnataka, India

Dr. Subhash Patil

Associate Professor,

Department of Orthopedics,

Raichur Institute of Medical

Sciences, Raichur, Karnataka, India
Corresponding Author: Dr. Subhash Patil Associate Professor, Department of Orthopedics, Raichur Institute of Medical Sciences, Raichur, Karnataka, India

\section{Management of tibial shaft fractures with reamed intramedullary interlocking nail: A prospective study}

\author{
Dr. Kanakachalapathi and Dr. Subhash Patil
}

DOI: https://doi.org/10.22271/ortho.2020.v6.i4a.2318

\section{Abstract}

Fracture shaft of tibia are increasing due to high velocity trauma and industrialization. Not only they are common but often difficult to treat. Until recently surgeons had to rely on non operative methods, ' $V$ ' nailing, 'plates and Screws' and external fixators but they had their drawbacks like prolonged immobilization, infection, delayed union, nonunion, malunion and cumbersome for patients. With the introduction of reamed intramedullary interlocking nail for tibial shaft fractures, it has overcome some of these complications and encourages the patients for early mobilization. This study has been done to evaluate the results and complications of reamed intramedullary interlocking nail for tibial shaft fractures in closed and Gustilos type I and II fractures. Thirty adult patients with fresh tibial shaft fractures were treated surgically with reamed intramedullary interlocking nail. Results: Among thirty patients treated with reamed intramedullary interlocking nail 24 fractures united at an average of 19.12 weeks with an union rate of $96 \%$. Two fractures showed delayed union, one fractures had non union and one fracture had malunion. One case had distal locking screws breakage. One case of deep infection and two cases of superficial infection were noted. Seven patients had anterior knee pain, one case developed shortening of leg which was less than $1 \mathrm{~cm}$. Functional results were graded according to the criteria by Klemm and Borner. $92 \%$ of patients achieved good or excellent results, fair results were obtained in one patient and in one patient the functional results were poor.

Keywords: Reaming, intramedullay interlocking nailing, tibial shaft fractures

\section{Introduction}

Tibia is the most commonly fractured long bone and the exposed anatomical location makes it vulnerable to direct blow and high energy trauma as a result of motor vehicle accident.

Tibia has precarious blood supply due to inadequate muscular envelope. Tibial fractures may be associated with compartment syndrome, vascular or neural injury. The presence of hinge joints at the knee and the ankle, allows no adjustment for rotatory deformity after fracture. Because of high incidence of complications, management often is difficult ${ }^{[1]}$.

Various modalities of treatment of fracture shaft of tibia are conservative gentle manipulation and use of short leg or long leg cast, open reduction and internal fixation with plates and screws, external fixation and intramedullary fixation with flexible nails (ender pins) and interlocking intramedullary nails with or without reaming.

Closed intramedullary interlocking nailing is accepted by most of the orthopaedic surgeons, as the treatment of choice in diaphyseal fractures but it is also associated with a number of complications ${ }^{[2]}$.

There are many controversial issues in the management of fractures of tibial shaft with closed intramedullary nailing. The question of reaming, its role in proximal third fractures and open fractures, is still being debated ${ }^{[3]}$. Its role in distal third fractures is fairly established provided two distal locking screws are put at right angles to each other and associated fibular fracture is fixed to avoid angulation ${ }^{[4]}$.

This is a prospective study to evaluate the results of reamed intramedullary interlocking nailing in both open and closed fracture shaft of tibia and to study the complications of reamed intramedullary interlocking nailing of fractures shaft of tibia.

\section{Methodology}

A prospective study of results and complications following reamed intramedullary interlocking 
nailing in both open and closed fracture of tibial shaft was done at department of orthopaedics, Raichur Institute of Medical sciences, Raichur from Dec 2017 to Dec 2018.

Thirty patients with fracture of the tibial shaft were selected for the study.

\section{Inclusion Criteria}

- Age more the 18 yrs

- Patients with closed fractures of tibial shaft

- Patient with open fracture of tibial shaft-Gustilo Anderson type 1 to type $3 \mathrm{~A}$

\section{Exclusion Criteria}

- Age less than 18 yrs

- Segmental fractures

- Patient with open fracture of tibial shaft Gustilo Anderson type $3 \mathrm{~B}$ and $3 \mathrm{C}$.

In total number of 30 patients admitted, there were 24 males $(80 \%)$ and 6 females $(20 \%)$. There were 18 closed fractures $(60 \%)$ and 12 open fracture $(40 \%)$ (GA type I-6, GA type II4).

The age of the patients ranged from 20 years to 60 years with a mean of 34.64 years. Most of the fracture were caused by high energy trauma by road traffic accidents accounting for 21 cases $(70 \%), 6$ cases were due to fall $(20 \%)$ and 3 were due to assault. 8 (32) patients had associate injuries.

There were 5(15\%) proximal third fracture, 19 (72\%) middle third fractures and $6(18 \%)$ distal third fractures.

The predominant fracture patterns were transverse in 12 (48\%), oblique $5(20 \%)$, spiral $3(12 \%)$ comminuted in 3

$(12 \%)$ and segmental in $2(8 \%)$ fracture.

Preoperative preparation of patients:

- Patients were kept NBM for 8-10 hours before surgery

- IV fluids as per the need were given

- Adequate amount of compatible blood if needed was arranged

- Preparation of whole extremity, private parts and back was done

- Written and informed consent was taken

- Soap water enema HS

- Tranquilizers HS

- IV antibiotics half an hour before surgery

- Shifting of the patients 30minutes before surgery to operation theatre

Preoperatively the length of the nail is calculated by subtracting 3 to $4 \mathrm{~cm}$ from measurement taken from the knee joint line to tip of the medial malleolus clinically and medullary canal is measured at the isthmus on X-rays. Accordingly a stock of interlocking nails $2 \mathrm{~cm}$ above and below the measured length and $1 \mathrm{~mm}$ above and below the required diameter were always kept. We have used cannulated tibial nails in our cases.

\section{Results}

Fifteen cases were operated under spinal anaesthesia, 9 under epidural anaesthesia and 1 case under general anaesthesia.

Table 1: Type of Anaesthesia

\begin{tabular}{|c|c|c|}
\hline Type of Anaesthesia & No. of Cases & Percentage \\
\hline Spinal & 18 & 60 \\
\hline Epidural & 9 & 30 \\
\hline General & 3 & 10 \\
\hline
\end{tabular}

Majority of the nails inserted were $9 \mathrm{~mm}, 4$ nails were of $10 \mathrm{~mm}$ diameter and 3 were of $8 \mathrm{~mm}$ diameter. 21 fractures were locked in static mode and 9 fractures were locked dynamically.

Table 2: Nail size

\begin{tabular}{|c|c|c|}
\hline Nail size & No. of Cases & Percentage \\
\hline $8 \mathrm{~mm}$ & 3 & 10 \\
\hline $9 \mathrm{~mm}$ & 21 & 70 \\
\hline $10 \mathrm{~mm}$ & 6 & 20 \\
\hline
\end{tabular}

Table 3: Mode of locking

\begin{tabular}{|c|c|c|}
\hline Mode of Locking & No. of Cases & Percentage \\
\hline Static & 21 & 70 \\
\hline Dynamic & 9 & 30 \\
\hline
\end{tabular}

All the cases were started with joint mobilization exercises on $1^{\text {st }}$ post-operative day. Partial weight bearing was delayed till 6 weeks irrespective of fracture configuration. The average period of commencement of full weight bearing was 12.8 weeks.

Table 4: Patient Mobilization

\begin{tabular}{|c|c|c|}
\hline FWB & No. of Cases & Percentage \\
\hline 12 weeks & 18 & 60 \\
\hline 14 weeks & 7 & 23.3 \\
\hline$>14$ weeks & 5 & 16.6 \\
\hline
\end{tabular}

The average time taken for union was 19.12 weeks, closed fracture united earlier at (18 weeks) Type I and Type II fracture took 18.86 weeks and 20.5 weeks respectively for union.

$96 \%$ of the fractures united with 2 fractures showing a delayed union and 1 (4\%), fracture going for nonunion.

Table 5: Fracture Union

\begin{tabular}{|c|c|c|}
\hline Type of Fracture & Average Time & Union Rate \\
\hline Closed & 18 weeks & 100 \\
\hline Type I & 18.86 weeks & 100 \\
\hline Type II & 20.5 weeks & 90.9 \\
\hline Total & 19.12 weeks & 96 \\
\hline
\end{tabular}

Skin grafting was done to cover the traumatic wound in 3 type II fractures whereas delayed primary closure was done in 1 cases.

Dynamization was done in 8 cases between 12 and 16 weeks depending on the progress of fracture healing.

Table 6: Secondary Procedure

\begin{tabular}{|c|c|c|}
\hline Procedure & No. of Cases & Percentage \\
\hline Skin grafting & 3 & 12 \\
\hline Delayed primary suturing & 1 & 4 \\
\hline Dynamization & 8 & 32 \\
\hline
\end{tabular}

The average range of motion in the knee joint was 135.6 degree, full ankle motion was observed in 20 patients. One patient showed a loss of $>25^{0}$ of motion at ankle compared to the normal side while 4 patients showed $<25^{\circ}$ of loss of joint motion.

One case $(3.3 \%)$ of deep infection was noted in the present study. Two patients $(6.6 \%)$ showed a superficial soft tissue infection.

One case $(4 \%)$ of malunion was found with an anteroposterior angulation of 10 degrees, one case $(3.3 \%)$ with a communited $\sim 41$ fracture showed a shortening of $<1 \mathrm{~cm}$. No cases of 
significant rotational deformities and varus or valgus angulation deformities was noted.

One case $(3.3 \%)$ of failure of distal screws was seen in a distal third tibial fracture. It did not affect the fracture healing. Six cases $(20 \%)$ complained of pain in the knee joint at final follow up. All were of mild variety and occurred on kneeling down.

Table 7: Complications

\begin{tabular}{|c|c|c|}
\hline Complications & No. of Cases & Percentage \\
\hline Malunion & 1 & 3.3 \\
\hline Superficial infection & 2 & 6.6 \\
\hline Deep infection & 1 & 3.3 \\
\hline Knee pain & 6 & 20 \\
\hline Implant failure & 1 & 3.3 \\
\hline Shortening & 1 & 3.3 \\
\hline Non union & 1 & 3.3 \\
\hline Delayed union & 2 & 6.6 \\
\hline
\end{tabular}

Functional results were graded according to the criteria by Klemm and Borner ${ }^{\text {[75] }}$ (1986). $90 \%$ of patients achieved good or excellent results, fair results were obtained in one patient and in one patient, the functional results were poor.

Table 8: Functional Results

\begin{tabular}{|c|c|c|}
\hline Functional Results & $\begin{array}{l}\text { No. of } \\
\text { Cases }\end{array}$ & Percentage \\
\hline \multicolumn{3}{|l|}{ Excellent } \\
\hline $\begin{array}{c}\text { Full knee and ankle motion No muscle } \\
\text { atrophy } \\
\text { Normal radiological alignment }\end{array}$ & 21 & 70 \\
\hline \multicolumn{3}{|l|}{ Good } \\
\hline $\begin{array}{l}\text { Slight loss of knee and ankle motion }(< \\
\left.21^{0}\right) \\
\text { Less than } 2 \mathrm{~cm} \text { of muscle atrophy } \\
\text { Angular deformity } \\
\end{array}$ & 6 & 20 \\
\hline \multicolumn{3}{|l|}{ Fair } \\
\hline $\begin{array}{l}\text { Moderate loss of knee and ankle motion } \\
\left(25^{0}\right) \text { Morethan } 2 \mathrm{~cm} \text { of muscle atrophy } \\
\text { Angular deformity }\left(5^{0}-10^{0}\right)\end{array}$ & 2 & 6.6 \\
\hline \multicolumn{3}{|l|}{ Poor } \\
\hline $\begin{array}{l}\text { Motion loss and knee and ankle motion } \\
\left(>25^{0}\right) \\
\text { Marked muscle atrophy Angular } \\
\text { deformity }\left(>10^{0}\right) \\
\end{array}$ & 3.3 & 4 \\
\hline
\end{tabular}

\section{Discussion}

Patients were encouraged to move knee and ankle joints on the $1^{\text {st }}$ post-operative day after the patient has recovered from anesthesia. Partial weight bearing was delayed till 6 weeks irrespective of the fracture configuration. Full weight bearing was allowed based on clinical and radiological assessment of fracture healing. The average period of commencement of full weight bearing was 12 weeks in the present study.

Eighteen patients $(60 \%)$ in the present study were allowed to full weight bearing by 12 weeks, 9 patients (30\%) were allowed to full weight bearing by 14 weeks and in 3 patients (10\%) the full weight bearing was allowed after 14 weeks.

Keating et al. ${ }^{[5]}$ in their study advised the patients to remain non weight bearing for the first 6 weeks after injury.

Larsen et al. ${ }^{[6]}$ allowed partial weight bearing of $15 \mathrm{kgs}$ for 6 weeks in early post-operative period. There were no cases of compartment syndrome, fat embolism or peroneal nerve palsy in the present study.

The results of the present study are comparable with those other studies. 23 fractures united in the present study with a mean union time of 19.12 weeks with a union rate of $96 \%$. Closed fractures united earlier (average time 18weeks) 42 compared to type I and II open fractures (average of 18.86 weeks and 20.5 weeks respectively). One case was comminuted type II fracture in a 27 year old male which united in $28^{\text {th }}$ week after dynamization. The second one case was associated a superficial infection at the distal screw site and took 26 weeks to show union. One case of type 1 open fracture involving middle third of tibia went for non-union despite dynamization the patient refused for further intervention.

Skin grafting was done to cover the traumatic wound in 3 type II fractures whereas delayed primary closure was done in 1 cases. All the procedures requiring soft tissue coverage were done after nailing.

The average range of knee joint was 141 degrees. (Range 128 - 161 dedress) and that of ankle movements was 84 degrees (range 45-109 degree) in tibial fracture treated by reamed nailing in a study reported by Larsen et al. ${ }^{[6]}$

Keating et al. ${ }^{[5]}$ reported a restriction of knee movements in $7 \%$ of cases and loss of ankle motion in $14 \%$ of cases.

The average range of knee joint motion in present study was 135 degrees and $76 \%$ of patients showed full ankle motion compared to the normal limb. One patient showed a loss of more than 25 degree of motion at ankle compared to the normal side while 4 patients showed less than 25 degree of loss of ankle joint motion.

Larsen et al. ${ }^{[6]}$ reported a malunion in 2 of 22 patients treated by reamed nailing.

Keating et al. reported a $6 \%$ rate of malunion in type I fractures and $3 \%$ rate in type II fractures.

One case $(4 \%)$ of malunion was found with as anteroposterior angulation of 10 degree had a fracture of upper third of tibia close to the tibial tubercle and only a single lacking screw could be inserted which could not hold the fracture in alignment.

Malalignment is a common problem in proximal third fracture treated with locked nails because of the large discrepancy in size between the tibial nail and the wide tibial diaphysis. Freedman and Johnson [7] found that $58 \%$ of proximal fractures were malaligned compared to $7 \%$ of middle third and $8 \%$ of distal third fractures. Singer et al. ${ }^{[8]}$ stated that it is imperative that the fracture be held reduced during nail insertion in case of proximal tibia fracture through use of bone clamps, a small plate or by using blocking screws. Refinements in technique, including more precise placement of the entry portal (a more proximal and posterior entry portal), extending the knee during insertion of the nail, using a nail with more proximally located bend, use of blocking screws, uncoritical plate $\mathrm{s}$ and two pin medial external fixation have been described to reduce the frequency of this complication.

Blachut et al. ${ }^{[9]}$ reported an infection rate of $0 \%$ in closed fractures in reamed nailing and $2 \%$ in closed fractures in unreamed nailing.

Court Brown et al. ${ }^{[10]}$ reported an infection rate of $6.9 \%$ in Gastilo type I fracture and $6.6 \%$ in type II fracture with reamed intramedullary nailing.

The current study had one case $(3.3 \%)$ of deep infection developed in the region of traumatic wound leading to purulent discharge in patient with a type II fracture 2 weeks after surgery. The wound was debrided and purulent material was sent for culture and sensitivity and appropriate antibiotics were instituted. The infection subsided with regular dressings of the wound. The fracture failed to unite even after dynamization. The patient refused further intervention.

Two cases $(8 \%)$ developed superficial soft tissue infection, one at proximal nail entry point and one at distal locking 
screw. One patient among the two was diabetic. They were treated by appropriate antibiotics, pus was sent for culture and sensitivity and appropriate antibiotics were instituted. The infection subsided with regular dressings of the wound and fractures united at 14 and 12 weeks respectively.

Singer et al. ${ }^{[8]}$ recommended use of antibiotics for 2 to 6 weeks in cases of infection associated with in intramedullary nailing. Keating et al. opined that adequate soft tissue and bony debrdement followed by sound soft tissue coverage is the key to minimize deep infection in open fractures of tibia irrespective of the type of fixation used. The use of antibiotic bead pouches reduces the incidence of infection further. If infection occurs, it is not necessarily a catastrophic complication and usually can be eradicated with prompt measures ${ }^{[5]}$.

One case of distal screw breakage developed in a patient with an oblique fracture who did not follow the non-weight bearing instruction in the early post-operative period. The patient was later mobilized with a patellar tendon bearing cast and the fracture subsequently united. No case of nail breakage was found.

Blachut et al. ${ }^{[9]}$ reported $2 \%$ incidence of screw failure in reamed nailing and $16 \%$ incidence of screw failure in unreamed nailing in 154 closed tibial fractures various comparative studies have demonstrated a significantly increased incidence of screw failure with unreamed nails. The increased risk of screw breakage is directly related to small diameter of the so called unreamed nails and screws, which are more prone to figure failure.

\section{Conclusion}

- High union rates, low incidence of complications including infection and good functional results suggested that reamed interlocking nailing technique is a satisfactory method of treating closed and open type I and type II tibial fractures.

- Reamed intramedullary interlocking nailing is a safe and effective technique for management of closed and "Gustilo Type I and Type II" tibial fractures. The method is safe and effective in achieving solid union with least number of complications.

\section{References}

1. Gustillo RB. Fracture of the tibia and fibula. In: Fractures and dislocations. Gustillo RB, Kyle RF, Templeman DC, Eds. $1^{\text {st }}$ Edn. Philadelphia: Mosby, 1992, 901

2. Watson Jones R, Cottact WD. Slow union of fractures with a study of 804 fractures of the shaft of the tibia and femur. J Bone and Joint Surg. 1942;30:260.

3. Charnley J. Fractures of the shaft of the tibia. In: The closed treatment of common fractures. $4^{\text {th }}$ Edn. Edinburgh: Churchill Livingstone, 1961,205-249.

4. Dehne E, Metzent, Reffer PA. Non operative treatment of the fractured tibia by immediate weight bearing. J Trauma. 1961;1:514.

5. Keating JF, O'Brien PI, Blachut PA, Meek RN, Broekhuyse HM. Reamed interlocking intramedullary nailing of open fractures of tibia. Clin Orthop. 1997;338:182-191.

6. Larsen LB, Madsen JE, Hoiness PR, Ovre S. Should insertion of intramedullary nails for tibial fractures be with or without reaming? A prospective, randomized study with 3.8 years follow up. J Orthop Trauma. 2004;18:144-149.

7. Freedman EL, Johnson E. Radiographic analysis of tibial fracture malalignment following intramedullary nailing. Clin Orthop. 1995;315:25-33.

8. Singer RW, Kellam JF. Open tibial diaphyseal fractures: Results of unreamed locked intramedullary nailing. Clin Orthop. 1995;315:114-118.

9. Blachut PA, O'Brien PJ, Meek RN, Broekhuyse HM. Interlocking intramedullary nailing with and without reaming for the treatment of closed fractures of the tibial shaft. A prospective, randomized study. J Bone Joint Surg. 1997;79A:640-646.

10. Court-Brown CM. Reamed intramedullary tibial nailing: An overview and analysis of 1106 cases. J Orthop Trauma. 2004; 18:96-101. 